http://dx.doi.org/10.12795/PH.1990.v05.i01.06

\title{
En torno a la Revolución...
}

Carmen Ramírez Gómez

«L'idée même de la Révolution comme instance et comme abstraction dépend de la capture d'un véritable instant sans lequel elle ne serait pas. Le moment-éclair de la guillotine (...)»1.

El 21 de enero de 1793 Louis XVI es guillotinado en la Plaza de la Revolución. La plaza se transmuta en Agora griega, cronotopo angular de la Historia que confunde biografía y «événement»: el cuerpo de Louis XVI es cuerpo de la Historia ofrendado al Ciudadano. Este acto crucial, «público y cívico», constituye una «mise en abyme» ${ }^{2}$ simbólica de todo el proceso histórico iniciado desde el feudalismo, la instauración de la Monarquía Absoluta hasta la Revolución de $1789^{3}$.

La Revolución, «como instancia y como abstracción», concentrada en el «moment-éclair» de la guillotina posee una dimensión «espectacular» cuyos parámetros espacio-temporales -la Plaza; 1793-y componentes objetales -la guillotina; el Reygeneran una evocación psico-sensorial particular del acontecimiento: Louis XVI y su verdugo, última escena del teatro del Antiguo Régimen.

El Siglo XVIII, en efecto, desarrolla una afición particular por el «espectáculo» tanto en el ámbito literario y estético en general como en su vertiente social.

\footnotetext{
${ }^{1}$ Raymond BELLOUR, «Dumas, l'homme d'une image», Magazine Littéraire, 258, (oct. 1988), Paris, p. 75.

${ }^{2}$ Relato especular.

${ }^{3}$ «Le constat s'impose au XVIII siècle d'une dégénérescene de la noblesse. Le thème s'aigrit et devient ouvertement polémique aux approches de la Révolution qui peut apparaître comme une lutte inégale» DELON, M. L'idée d'énergie au tournant des Lumières (1770-1820). Tesis de estado dirigida por R. Mauzi, 1985, pp. 309-10.
} 
Desde las fiestas galantes de Versailles, las mascaradas de las favoritas hasta los palcos de la Opera y del Teatro, se estructura un espacio escénico que proyecta esta inclinación por la imagen, la mostración, la representación. El Siglo de Las Luces ha sabido armonizar los arabescos de la estética Rococó ${ }^{4}$ y el lenguaje depurado del pensamiento del Aufklärug.

En una perspectiva social, la teatralización está asociada a la figura estelar del Rey, de Dios, que ordena y consume a la vez la aparatosidad propia del Antiguo Régimen, ostentación ligada a los valores de la Nobleza y de la Tradición.

La fascinación del Siglo XVIII por la extroversión, en el sentido de espectáculo, se materializa tanto en la figura del Rey Sol como en la época de la Regencia. Louis XV nacía libertino: el lujo, los bailes, la exuberancia consagran este «voyeurisme» fruto de la escenografía constante: Versailles, las Tuileries representan el decorado privilegiado de estos espectáculos del Pasado y del vértigo narcisista de la Aristocracia. Público y actor -la casta de los Privilegios- entretienen una relación de mímesis absoluta, perpetuando las paradojas del Cómico: duplicidad e ilusión, «le théâtre est le lieu où l'élite se donnee en spectacle à elle-même, (...)»5.

«Le sentiment forcené du spectacle prend la cruauté en charge; la place publique se confond avec l'éspace théâtral. Les têtes tombent sous les applaudissements» ${ }^{6}$.

El estallido colectivo supuesto por la Revolución -punto culminante de un proceso de construcción- destruye todos los fundamentos del statu quo así como las representaciones y modos de representaciones correspondientes.

Los lugares cerrados, «topologie lourde de signification morale» ${ }^{7}$, claustros del divertimento y de la exhibición aristocrática, se destructuran en espacios abiertos: la plaza pública, como lugar de Fiesta y asamblea delimita los contornos del foro revolucionario.

Cristaliza una teatralidad nueva, modelizada en sus vertientes estética, cultural, social a partir de una organización política basada en los presupuestos democráticos. La participación, el consenso, conceptos adscritos a la irrupción de las Masas en la escena

${ }^{4}$ Los límites entre Rococó y Neo-clacisimo son difíciles de establecer con rigor. La publicación de la Enciclopedia, a mediados del XVIII, puede servir de referencia cronológica para fijar el momento clave de la decadencia barroca.

${ }^{5}$ DELON, M. et Altri, Littérature Française. De l'Encyclopédie aux méditations, Paris, Ed, Arthaud, 1984, Vol. 6, p. 178.

(El teatro como espectáculo y como género literario reproduce el caracter elitista y el modelo monocéntrico de la Aristocracia. El teatro erúdito predominarè a lo largo del XVIII, si bien, de forma coetánea, con la Comédie Italienne, teatro popular, garante de una larga tradición de libertad).

${ }^{6}$ WALDLASOWSKI, P., Libertines, Paris, Gall., 1980, p. 70.

${ }^{7}$ DELON et Al., op. cit., p. 97. 
política, promueven otros rituales ${ }^{8}$ que cobijan los gérmenes de otra sagralidad: Napoleón está en el recodo de la senda revolucionaria.

La Fiesta Pública constituye el espectáculo oficial del Nuevo Orden. La dimensión teatral permanece: público y actor se esparcen por las calles de Paris dibujando «un espace révolutionnaire, polarisé autour de quelques hauts lieux, la Bastille et le Champs de Mars, l'Assemblée et l'ancienne Place Louis XV, devenue la place de la Révolution $(. ..) »^{9}$.

La nueva escena se compone de lugares abiertos canalizando el flujo incesante de las masas revolucionarias, movimiento que simboliza el carácter expansivo y energético del Siglo Ilustrado ${ }^{10}$.

El escenario se había regenerado ${ }^{11}$, despojado de los símbolos absolutistas. El advenimiento de la guillotina renovaba el complejo de la maquinaria ${ }^{12}$ teatral, dispositivo esencial de una ficción arrojada definitivamente de la Historia: el eje de la Modernidad giraría para siempre en torno al Hombre -instaurándose un nuevo Humanismo acorde con la idea de palingenesia-. La catarsis aún no estaba completa. El último delirio de ficción del Antiguo Régimen se revelaría , una vez más, a través del Monarca: Louis XVI guillotinado.

«On ne sort de la fiction que pour tomber dans les mains du Bourreau. C'est la grande vengeance névrotique et bourgeoise du Réel pur et simple» ${ }^{13}$.

La muerte de Louis XVI representa, de una forma terminante, no sólo la emancipación de la Historia de los yugos del Antiguo Orden, sino también, a través de

${ }^{8}$ Tras la muerte de Robespierre, la fiesta pública decae. El ritual revolucionario, nacido del primer estallido en 1789, adopta las formas del desfile militar. Bonaparte utilizará los contornos en este escenario democrático para inferirle contenidos imperiales.

9 Ibid., p. 96.

${ }^{10} \mathrm{El}$ concepto «energía» constituye una idea clave en el siglo XVIII. «(...)L’énergie est création linguistique, esthétique, intellectuelle et politique. Elle marque de son accent le savoir conquérant de l'Encyclopédie, l'utopisme de la Révolution et de l'Empire, l'imagination créatice de l'illuminisme et du Romantisme. Elle bouscule les manichéismes moraux et esthétiques et les dualismes figés. L'energie de la sensation, de l'action, de l'invention littéraire dépasse une opposition statique du plaisir et de la douleur, du bien et du mal, de la beauté et de la laideur. L'idée d'énergie aide le matérialiste à réunifies la matière et le mouvemente, le corps et l'âme(...)». Delon, op. cit., pp. 630 - 31 .

${ }^{11}$ Las nociones de «regeneración» y de «palingenesia» suponen una nueva concepción de la Historia basada en el movimiento y en el progreso.

El Hombre mira hacia atrás, tomando la Antigüedad Clásica como modelo tanto en el ámbito ideológico, filosófico como en la estética, el modelo clásico, ya no como canon académico sino referencia de estilización y naturalidad. (Ver a este efecto las obras cit. de DELON).

12 El siglo XVIII inaugura la era del «maquinismo».

Por otra parte, la máquina desempeña un papel importante en el imaginario del Siglo Ilustrado. En efecto, la máquina implica el derrumbamiento de cualquier posible heroicidad en el Individuo.

${ }^{13}$ WALDLASOWSKI, P., op. cit., p. 140. 
la mutilación del Cuerpo Real, metonimia del Regimen Absolutista, el desvanecimiento de una mitología y un imaginario basado en el «cuerpo» como modo de representación.

El «cuerpo» como idea, concepto, materia subyace en el magno edificio teórico y filosófico elaborado a lo largo del Siglo XVIII: los dos grandes sistemas filosóficos modernos, racionalismo y sensualismo, se recortan mutuamente los presupuestos ideológicos, argumentando sine die acerca de los dilemas esenciales de la naturaleza humana: cuerpo VS alma; carne VS espíritu; instinto VS razón; pulsión VS conciencia. Frente al cogito cartesiano, Helvetius opone los sentidos como motores fundamentales de la existencia. El sensualismo fisuraba el armazón racionalista, abogando a favor del cuerpo como principio activo en la relacion con el mundo y con las cosas.

El «cuerpo» constituye pues, una categoría ineludible en la aprehensión y comprensión del Siglo de Las Luces, y un vector de incidencias y derivas que, sin explicar la Revolución -es evidente- traduce una ensoñación subversiva de la Historia construida sobre los mecanismos complejos de la ficción.

La ficción -entendida como realidad Re-codificada e interiorizada y como apariencia, artificio, irrealidad-se traduce (en la sombra, el Rey siempre), en una serie de simulacros y ritualizaciones cuyas manifestaciones se ilustran a través del aparato social, moral y ético así como en una de sus formas predilectas de expresión: la escritura libertina.

Entre el código social, condensador de todos los valores del modelo político vigente -la decadente Monarquía Absoluta- y la escritura libertina, recodificadora igualmente del paradigma del Poder, se establece una red significante basada en el cuerpo como étimo social y psiconsensorial. Las esferas aristocráticas reproducen en la práctica mundana y a través de las doxas galantes las relaciones jerárquicas del sistema absolutista consagrándolo a través del artificio y de las «mises en scènes» barrocas; subvertiéndolo a su vez en una escritura que libera la espiral de «relaciones peligrosas» que anulan paulatinamente el efecto del Cuerpo Real, como metonimia del Orden, en cuya oquedad se instala el cuerpo, instancia de Eros. La seducción, otra estrategia de poder, mina no tanto la máquina socio-política como los fantasmas y modelos imaginarios en los que se fundamentan el asentimiento colectivo ${ }^{14}$.

El cuerpo es imposible como existencia individual: -implica una concepción dialéctica del individuo en relación con el mundo y las cosas a partir de la afirmación del $\mathrm{Yo}^{15}$-. En los rituales mundanos -el atuendo diciochesco, la «perruque poudrée», les «mouches», la máscara-: el cuerpo es metáfora, ocultándose en la mostración del objeto. Por otra parte, se elabora su desmontaje como «Cuerpo Real» a través del pensamiento ilustrado que rehabilita todos los componentes físicos e inmediatos de la existencia, incorporando en el concierto de la Naturaleza y de la Razón los sentidos, la noción de placer, las sensaciones, la «jouissance» y por consiguiente, el cuerpo -fisis y psiquecomo principio y receptáculo de movimiento, de creación: la Ley unificadora de la Voluntad despótica ha sido quebrantada a cambio de la emancipación del individuo

${ }^{14}$ Cf. BAUDRILlard, J., De la séduction, Paris, Ed. Galilé, 1979.

${ }^{15}$ Delon hace referencia a una «dialectique du repliement et de l'expansion qui caractérise la sensibilité au toumant des Lumières». DELON, M. op. cit., p. 412. 
capaz de percibir el significado del universo como totalidad y el status del Yo en el macro-cosmos. La rehabilitación del cuerpo suponía la desacralización paulatina del Rey como institución y como idea.

El cogito libertino substituye al cogito cartesiano: sentir es existir, al menos soñar la sensación. La literatura libertina no escapa a la imposibilidad del cuerpo, ni al aura obsesiva de la ficción a través de los rituales de la parada erótica y en la seducción en sí -entendida como estrategia narcisista: poseerse en el otro, delirios de la autosuficiencia y así mismo proyecta la estructura de poder y la dimensión constrictiva del principio de autoridad.

Por otra parte, desde esta trampa de la ficción la práctica libertina subvierte el paradigma tutelar: la experiencia del cuerpo como «jouissance» basada en una mecánica de elección, variedad e inmediatez constituye un micro-cosmos regido por la movilidad. Tanto en la posesión del otro como en su propia transitividad, el Yo libertino se desprende de toda filiación vertical. Los lazos familiares y Dios, pilares del edificio absolutista, se quebrantan a través de la libre circulación de los cuerpos, de las sensaciones. La ensoñación erótica resultante de esta dinámica expulsa de su lógica la sistemática del statu quo.

El goce libertino requiere una multiplicidad que le permita diseminar placeres, arrojar y recoger energía, a partir de sí mismo y para sí mismo.

A semejanza de la Naturaleza, el eros libertino es pródigo: su modelo existencial tiende a la expansión, a la re-creación cósmica a partir de un Yo individual, vertebrador y receptor de su propia acción. La desnuclearización operada por la experiencia erótica derroga el concepto de colectividad y de sistema social coherente, amparado por una Ley Provindencial.

A través del deseo, de la experiencia gozosa de los sentidos, el cuerpo cumple con las potencialidades de la naturaleza y de la contemplación del Yo auténtico. La rehabilitación de los placeres implica la revaloración de una Naturaleza desvirtuada por el Poder y la Autoridad. La consagración del Individuo conlleva esta recuperación cósmica a la vez que se opera la desacralización del Cuerpo Real.

En la ensoñación erótica de la realidad social y política se perfila una ensoñación subversiva de la Historia: la revolución de los sentidos, la práctica erótica -no como sustituto del Cuerpo Real sino como individualización del cuerpo- entraña el desmontaje de las categorías derivadas del sistema absolutista: la imagen y la proyección de la figura del Monarca quedan expulsadas de la estructura ideológica. Frente a la experiencia de lo real y de, la percepción histórica del universo-, la visión mítica de la Historia se deshace.

En la clausura del Boudoir, sancturario de la transgresión libertina, la lenta mutilación del Cuerpo Real ha agotado progresivamente la ficción.

El espacio cerrado, metonimia del edificio de un paradójico despotismo ilustrado se ha resquebrajado hasta derruirse. Se regenera el espacio, la antigua plaza Louis XV será la plaza de la Revolución: Louis XVI era guillotinado en su propia ubicidad; muerte de la muerte. La Revolución había acometido su obra más perfecta: la Historia rescatada 
por el infinito poder del hombre, la experiencia de la Historia como absoluta destrucción, paradójicamente nunca perfecta, reencarnándose siempre. El cesarismo napoleónico erigía su Imperio desde la Revolución. 